\title{
EAl Endorsed Transactions

\section{Influence of Motivational Design Techniques on Use and Acceptance of Self-Management Health Systems in Older Adults}

Ine D’Haeseleer ${ }^{1,2, *}$, Jamie Schoofs ${ }^{3}$, Kim Schutters ${ }^{3}$, Dominique Schreurs ${ }^{4}$, Vero Vanden Abeele ${ }^{1,2,+}$

${ }^{1}$ KU Leuven, e-Media Research Lab, Andreas Vesaliusstraat 13, 3000 Leuven, Belgium

${ }^{2}$ KU Leuven, Dep. Computer Science, Celestijnenlaan 200A, 3001 Leuven, Belgium

${ }^{3}$ Triamant, Halingenstraat 76, 3806 Velm, Belgium

${ }^{4}$ KU Leuven, ESAT-WAVECORE, Kasteelpark Arenberg 10, 3001 Leuven, Belgium

\section{Abstract}

INTRODUCTION: Self-Management Health Systems (SMHS) are envisioned to support older adults and contribute to ageing in place. To promote the use and acceptance of SMHS, designers may resort to using motivational design techniques (MDT).

OBJECTIVES: This paper investigates how and which older adults prefer MDT in SMHS and whether these preferences are mediated by either motivation for health management (MHM) or mobile device proficiency (MDP).

METHODS: Based on a user evaluation with 45 older adults (mean age=84, SD=6.75), $32 \mathrm{MDT}$, MHM, and MDP were polled through questionnaires and informal interviews.

RESULTS: Findings showed that most techniques were welcomed, but also that scores vary widely, reflecting heterogeneity in the population and calling for caution in its implementation. These findings are then translated into implications for design.

CONCLUSION: Overall, older adults welcome MDT in SMHS. However, MDT are no panacea; tailoring MDT to users' needs is therefore crucial.

Received on 31 August 2021; accepted on 16 October 2021; published on 24 November 2021

Keywords: Self-Management Health Systems, Older Adults, Motivational Design Techniques, Motivation Healthy Lifestyle, Mobile Device Proficiency

Copyright ( 02021 Ine D’Haeseleer et al., licensed to EAI. This is an open access article distributed under the terms of the Creative Commons Attribution license, which permits unlimited use, distribution and reproduction in any medium so long as the original work is properly cited.

doi:10.4108/eai.24-11-2021.172219

\section{Introduction}

Self-Management Health Systems (SMHS) are integrated technical systems that combine monitoring of vital parameters via sensors (e.g., blood pressure monitors, glucose measures, weight scales, sleep monitors, activity trackers) and via self-reports (e.g., pain scales, mood surveys, disease activity logbooks) with risk assessment and decision support. SMHS are envisioned as particularly useful to help older adults monitor their

\footnotetext{
${ }^{*}$ Corresponding author. Email: ine.dhaeseleer@kuleuven.be

${ }^{\dagger}$ Principal corresponding author. Email: vero.vandenabeele@kuleuven.be
}

own health and well-being, thus contributing to ageingin-place [1-3], and ultimately mitigating the burden on health care provision $[4,5]$. Consequently, many current research efforts are geared towards the development of SMHS for older adults, e.g., [1, 3, 5-9]. Much of these research efforts focus on advancing the technical state-of-the-art concerning SMHS. However, to ensure uptake, it is also important to gain insight into older adults' attitudes towards using an SMHS and how to design these systems to ensure older adults are (more) motivated to self-manage health.

Recent studies on the adoption of these systems show conflicting results $[5,10-14]$. Some studies portray a bright future for SMHS, as their results show that older 
adults are interested in following up on their health, and welcome sharing this information with caregivers $[6,14]$. Other authors are more critical when discussing their findings, and highlight the different barriers for use and acceptance of SMHS [5, 10-13, 15]. Barriers include, among others, a lack of knowledge in how to maintain health and how to interact with technologies $[10,13-16]$, physical restrictions $[11,14,15]$, cost $[3$, $15,16]$, a lack in perceived usefulness $[3,5,10-13,16]$, distrust in the accuracy of tracking [13], and an overall distrust in technology [17].

To alleviate some of the aforementioned barriers, and to improve uptake and use of SMHS by older adults, designers might turn to motivational design techniques (MDT), i.e., behaviour change techniques intentionally embedded in technologies, "to arrange resources and procedures, and bring about changes in people's motivation" [18]. In other words, MDT are an umbrella term for persuasive system design principles (such as giving praise or offering reminders) [19], and gamification strategies (such as setting challenges and providing rewards) [20-22]. The use of MDT in fitness and well-being apps has grown exponentially in the past decade, e.g., Fitbit ${ }^{1}, 8$ fit $^{2}$, Strava ${ }^{3}$, or Nike Training $\mathrm{Club}^{4}$, and now has also found its way into SMHS [2326].

Studies investigating motivation of older adults to increase their physical activity showed that engagement was higher when using gamification techniques, e.g., by providing goals or stages of difficulty [27]. However, MDT are no panacea; it has been shown that not all MDT are equally welcomed. MDT related to socialising or self-monitoring seemed to be most preferred, whereas virtual rewards or competition were least preferred by older adults [28, 29]. Therefore, designers of SMHS targeting older adults need to know which specific MDT motivate older adults to use interactive systems to manage their own health and which MDT do not.

Such studies on SMHS for older adults are thus far limited, with the exception of van Velsen et al. [30]. These authors found that preferences for MDT indeed differ among older adults, but furthermore, preferences are associated with initial levels of intrinsic, extrinsic and amotivation. Recent studies in different fields have echoed similar findings [31-35]. These studies equally show initial levels of motivation towards behaviour that influence the preference for specific MDT. Hence, merely charting older adults' preferences for specific MDT is insufficient; a better understanding of how

\footnotetext{
$1_{\text {www.fitbit.com }}$

2 www.8fit.com

${ }^{3}$ www.strava.com

${ }^{4}$ www.nike.com/be/ntc-app
}

these preferences are mediated by initial motivation for self-management of health deserves further scrutiny.

It is also important to better understand the impact of technological aptitude on preference for specific MDT. Overall, among the older population, the number of computers, notebooks, and particularly mobile devices (both smartphones and tablets) keeps growing each year [36, 37]. Nevertheless, recent studies reconfirm that older adults still encounter difficulties when interacting with everyday technologies [10], including SMHS [5, 38] even when deployed on tablet or smartphone [12]. It is well documented that this lack in perceived ease of use $[11,39-43]$ negatively impacts attitudes of older adults towards ICT and health technologies. Therefore, it is plausible that older adults' technological proficiency also impacts preferences for MDT embedded in SMHS.

Present Objective. In summary, designers of SMHS need a better understanding of which specific MDT motivate older adults to use SMHS to manage their own health, as not all MDT are equally preferred by older adults. Moreover, preferences may be related to initial motivation toward self-management of health and technological proficiency. Knowledge of these relationships may also help designers of SMHS by tailoring MDT to the individual older adult and contributing to the uptake of SMHS by older adults to self-manage health. Therefore, the present study aims to investigate preferences for different motivational strategies. Furthermore, we aim to investigate how preferences for MDT are related to initial motivation to maintain a healthy lifestyle and technological proficiency. By providing insights on the motivations of older adults towards following a healthy lifestyle and the role of MDT, we aim to inform designers of SMHS on which and particularly how MDT are worth implementing.

\section{Background}

In the paragraphs below, we first discuss what constitutes MDT for health. Next, we present literature on motivational design and older adults. We end this section with a discussion of older adults and attitudes towards health technologies.

\subsection{Motivational design for health}

Motivational design is the umbrella term used to describe the use of a combined set of gamification strategies, persuasive principles and behaviour change techniques, such as giving points, awarding actions with badges, staging behaviour by providing goals and levels, stimulating competition by group challenges and leader boards, giving feedback using progress bars and graphs, providing triggers through notifications 
and reminders, etc. [44]. Within a health context, MDT have the specific aim to form or reinforce healthy attitudes and behaviours, often with the aim to increase compliance to a therapeutic regimen, e.g., $[45,46]$, ensure adherence to a drug treatment, e.g., $[47,48]$, or to support overall disease management, e.g., $[22,49]$.

In the past decades, motivational design has boomed $[22,32,33,50]$, and myriad taxonomies and models exist that enlist and categorise the diverse MDT and link them to the theoretical backgrounds $[18,51-$ 54]. MDT have been particularly popular in mHealth, i.e., health apps to be displayed on a smartphone or tablet, and supported by sensors embedded in the mobile device or extended with wearables. For mHealth apps, Geuens et al. [55] selected 26 MDT termed as lenses, based on applicability and theoretical background. These 26 lenses were clustered into six different categories, depending on whether the techniques primarily strengthen the ability to perform the health behaviour itself, reinforce the insight $\mathcal{E}$ awareness of personal health behaviour, give information on the disease in general, provide incentives through praise and rewards, support social interactions, or increase general trustworthiness \& likeability of the app.

In subsequent studies, the authors found that patients with chronic arthritis particularly welcomed MDT supporting an ability to perform the behaviour, reinforce personal insight in the disease, provide information, or increase trustworthiness [55]. In contrast, preferences for MDT related to incentivisation varied among older adults and were overall less favoured [55]. Most surprisingly, MDT targeting social support were strongly disliked [55]. The dislike for MDT centring on social support were reconfirmed in a study on SMHS to support adolescents recovering from pectus surgery [56]. Authors hypothesised that while patients value social support, when it comes to disease management, "every patient hurts in their own way" [55]. Moreover, they do not want relationships with peers to be mediated by SMHS and the intricacies of their disease [56].

\subsection{Motivational design and older adults}

Motivational design in health has gained popularity in recent years. However, most often, these studies are targeting either a younger population [57-59] or a specific disease, e.g., [60, 61]. Studies on gamification for older adults are thus far scarce [27, 29, 50]. A recent literature review by Koivisto and Malik [50] investigated research studies on older adults (aged over 55) and gamification. Out of the 12 studies, six focused on improving cognitive performance, i.e., brain training, five focused on physical health conditions, and one focused on mental health. While the systematic review found that most studies tend to have a positive stance towards gamification in older adults, no study was found that focused on self-management of health. To the best of the authors' knowledge, thus far, only one study explicitly studied the use of MDT for selfmanagement of health by older adults. Based on a web-survey with 212 older participants, van Velsen et al.[30] investigated which persuasive techniques are preferred most to manage a healthy lifestyle. In line with the aforementioned studies with patients [55, 56], they found older adults to dislike incentivisation through praise. Nevertheless, surprisingly, older adults also disliked MDT related to providing progress information, i.e., personal insight. Most liked was the MDT that provided 'real' incentives, i.e., coupons.

Perhaps most interestingly, the authors also found that initial motivation for maintaining a healthy lifestyle is related to preferences for MDT. The theory used by van Velsen et al.[30] to ground this hypothesis is the self-determination theory (SDT) [62], a widespread and elaborated theory when studying the importance of motivation for behaviour change in health and sports $[63,64]$. According to SDT, people differ in the extent to which they internalise the regulation of their drives for a certain behaviour, ranging from fully internal (autonomous or intrinsic) to fully external (controlled) motivation. Additionally, people can also be amotivated, possessing neither internal nor external regulations to perform a certain activity [62].

The authors showed that all preferences for persuasive techniques had a positive relationship with the intrinsic motivation to maintain a healthy lifestyle. However, only some MDT were related to extrinsic motivations [30]. Amotivation was not associated with any preferences towards persuasive techniques. Hence, although preliminary, these findings suggest that initial motivation towards health behaviour mediates preferences for MDT.

\subsection{Older adults' proficiency with and attitudes towards health technologies}

Next to the motivation of older adults to selfmanage their health, technological aptitude may also be of interest when investigating preferences for MDT. Several studies have shown that as age increases, technological proficiency decreases, e.g., [65, 66]. Older adults have less experience with currentday technologies [67], and may face difficulties in interacting with technologies because of age-related decline $[66,68]$. The struggles of older adults with health technologies have also been documented, e.g., $[10,38,69]$. In turn, less technological proficiency may influence attitudes towards technology, health-related technology, and the preferences for MDT that these systems embody. 
Hauk et al. [70] conducted a meta-analysis based on literature studying chronological age and technology acceptance, showing that age is negatively correlated with perceived ease of use and perceived usefulness, in turn impacting the intention to use technology, i.e., behavioural intention [40].

\section{Research objective}

The aim of this research study is to investigate older adults' preferences for MDT and possible associations with motivation to manage a healthy lifestyle and technological aptitude. These results can help designers of SMHS to gain insights into which MDT are worth implementing and how to tailor these to initial levels of motivation and/or technological proficiency. Therefore, the following three research questions will be investigated.

RQ1. What are the preferences of older adults towards different motivational design techniques? RQ2. Does motivation for health management mediate the preference towards motivational design techniques? RQ3. Does mobile device proficiency mediate the preference towards motivational design techniques?

\section{Method}

To investigate the preferences of older adults towards MDT in SMHS, a mixed-methods approach was used. First, structured interviews were conducted to gather data pertaining to the level of motivation to self-manage health, technological proficiency and preferences for 32 MDT. Interviews were analysed quantitatively and qualitatively. Ratings for each of the features were analysed and associations with motivation to manage a healthy life and technological proficiency were computed. Then, verbal utterances and explanations were analysed qualitatively to further the understanding of a specific scoring.

\subsection{Measurement Instruments}

Three questionnaires were included in this study: Motivation for Health Management scale, based on van Velsen et al. [30], Mobile Device Proficiency questionnaire [71], and Motivational Design Techniques questionnaire [22]. For all questionnaires, a trained interviewer administered the questionnaire items, both verbally and in written form. The interviewer also provided extra clarification or assistance if needed.

The Motivation for Health Management (MHM) scale investigates motivation towards following a healthy lifestyle, polling for intrinsic motivation, external motivation, and amotivation. This MHM is based on the questionnaire used in van Velsen et al. [30], which in turn was adapted from the Sports Motivation Scale
Table 1. All statements ("I would like to use a self-management health system, because...") from the motivation scale for health monitoring, divided over intrinsic (INT), extrinsic (EXT), or amotivation (AMO). Statements are based on the study from (author?) [30] and extended with two more items for amotivation (AMO3 and $\mathrm{AMO} 4)$.

\begin{tabular}{cl}
\hline item & question \\
\hline INT1 & $\begin{array}{l}\text { Because I like to learn more about following up on my } \\
\text { health. } \\
\text { BNT2 } \\
\text { Because I like to discover new ways to follow up on my } \\
\text { health. } \\
\text { Because I think it is very interesting to learn about how to } \\
\text { follow up on my health. }\end{array}$ \\
INT3 & $\begin{array}{l}\text { Because I think it is a good way to develop my strong suits. } \\
\text { Because I think it is one of the best ways to develop other } \\
\text { sides of myself. }\end{array}$ \\
INT5 & $\begin{array}{l}\text { Because the people that are important to me would be } \\
\text { angry at me if I did not. } \\
\text { EXT2 }\end{array}$ \\
EXT2ause I would then be appreciated by the people I know. \\
EXT3
\end{tabular}

(SMS-II) [72]. It contained 13 items, 4 or 5 items each that poll for the aforementioned three motivational constructs to which answers are measured with a Likert scale, varying from 'totally disagree' (-3), over 'neutral' (0), to 'totally agree' (3), see Table 1 for the specific items per construct.

The Mobile Device Proficiency (MDP) questionnaire investigates the skills of participants regarding using a mobile device [71], described as "a device that allows you to perform many of the same tasks as a standard computer but without the use of a physical keyboard and mouse". The MDP questionnaire consists of 46 questions, divided over eight categories: basics, communication, data and file storage, internet, calendar, entertainment, privacy, and troubleshooting and software management. The questionnaire is completed on a conditional basis, i.e., when a participant answers never having used a mobile device, all other statements below can automatically be completed with 'never tried'. A similar approach can be applied for sub-categories, e.g., if a participant indicates to the statement 'open email' to never have used emails, then all subsequent questions can be skipped and completed as 'never tried'. This allows completing the questionnaire efficiently and naturally. All questions will be answered with a 5-point Likert 
scale going from 'never tried' (1) to 'very easily' (5). The final score is calculated by averaging the scores for each of the eight categories, and then sum up the different categories, as stated in [71]. The total MDP score can vary between 8 and 40 ; a score of eight implies a participant has never used a mobile device at all. The maximum score of 40 implies a participant answered all statements of all eight categories with 'very easily'.

The Motivational Design Technique (MDT) questionnaire was composed of the 26 Lenses of Motivational Design for mHealth as used to investigating preferences towards motivational design technique by Geuens et al. [22]. These MDT were supplemented with eight additional persuasive techniques explored by van Velsen et al. [30]. Hence, in total, the questionnaire contained 32 MDT, listed below, and evaluated on a 7-point Likert scale ranging from -3 , over 0 , to +3 . A score of -3 implied that participants strongly felt that "the application would be worse if this was included", 'neutral' (0) reflected an " do not really care whether this is or is not integrated", and a score of +3 implied that participants strongly felt that "the application would be better if this was included".

\subsection{Data analysis}

All results were analysed via Python, Jupyter Notebook [73], including the libraries: numpy [74], pandas [75], matplotlib [76], scipy [77], and seaborn [78].

\subsection{Participants}

Participants were recruited via a local community centre Triamant [79]. Inclusion criteria for participants were that they were at least 65 years old, lived (semi) independently in a living unit, and scored at least 20 on the Mini-Mental State Examination (MMSE) [80]. These inclusion criteria ensure that participants are cognitively strong enough to understand this study's purpose and give their own consent. This study was approved by the Social and Societal Ethics Committee (G-2019 12 1931).

\subsection{Procedure}

All eligible participants were contacted and informed about the study. When participants were interested, a visit was arranged to review and sign the informed consent. Afterwards, participants were shown an example of an SMHS on a tablet, which they could interact with and test at their own pace to have a basic understanding of what an SMHS entails. For more information on the tablet application, we would like to refer to earlier work [9]. Next, the three questionnaires were taken. Besides the structured interviews, when polling for preferences for MDT, participants were welcomed to explain the scores further and encouraged to clarify their answers in an open-ended manner. To support the qualitative analysis of participants' answers, these interviews were audio-recorded.

\section{Results}

\subsection{Participants' information}

For this study, 47 participants were recruited. Two participants decided to quit early; one participant stopped during the MDT questionnaire; the second participant stopped after answering the questions regarding motivation to manage health. These two participants were, therefore, excluded from further data analysis. Of the remaining 45 participants, 27 older adults identified as male, 18 identified as female. Ages ranged from 65 to 97 years (mean age $=84, \mathrm{SD}$ $=6.75)$. Most participants $(n=34)$ lived alone in their living unit, 11 were living in the company of their spouse or another family member.

\subsection{Motivation for Health Management (MHM)}

In line with the procedure in [30], a factor analysis was conducted on the 13 items with orthogonal rotation (varimax) to verify the measurement of the three different types of motivation. The Kaiser-MeyerOlkin (KMO) test measure verified the suitability for the analysis with $\mathrm{KMO}=0.66$. Bartlett's test of sphericity $\chi^{2}=252.32, \quad p=0.0$, indicated that correlations between the items were sufficiently large for the factor analysis. Three components had an eigenvalue above one, based on Kaiser's criterion or the scree plot. Table 3 shows the pattern matrix with factor loadings after rotation. Component 1 (C1) clustered all items from intrinsic motivation (INT2$5)$, excluding the first initial item. Component 2 (C2) clustered items based on external motivation (EXT1-4). Finally, component 3 (C3) clustered all items regarding amotivation (INT1 $1_{\text {reversed }}$ and AMO14 ), where it was noted that INT4 (initial item on the intrinsic scale) mapped negatively on this cluster. Afterwards, Cronbach's alphas were calculated, shown in table 3; all three clusters, intrinsic motivation, extrinsic motivation, and amotivation scored high on internal reliability with $\alpha>$.7.

Based on these measurements of the different levels of motivation, results show that participants scored slightly positive on intrinsic (mean $=0.72, \mathrm{SD}=1.44$ ), and extrinsic motivation (mean $=0.60, \mathrm{SD}=1.45$ ) towards following a healthy lifestyle. In contrast, they scored negative on amotivation (mean $=-1.38$, $\mathrm{SD}=1.16$ ). Moreover, we noted overall high standard deviations, suggesting differences in the different levels of motivation among older adults. 
Table 2. Overview different motivational design techniques.

motivational design technique
INFORMATION
micro-tailoring
health education
fear appeal
macro-tailoring
simulation

item

specific information based on what the systems knows about the user general information about a healthy lifestyle and quality of life possible negative consequences of a current lifestyle, by giving extra insights information for target population, e.g., men/women, ages representation of a change in life when reaching a goal, e.g., how much money you would save when quitting smoking source

$[22]$

[22], [30]

TRUSTWORTHINESS \& LIKING surface credibility personalisation

avoiding advertisements in the application

adapting application to own needs and wishes, e.g., change contrast, enlarge text/buttons, audio, etc.

expertise receiving information about who designed and developed the application and their competences

verifiability receiving links to scientific sources

AWARENESS \& PERSONAL INSIGHTS

progress

logging

self-monitoring

tracking

self-goal setting

automatic goal setting

\begin{tabular}{|c|}
\hline $\begin{array}{l}\text { ABILITY } \\
\text { rehearsal } \\
\text { tunneling }\end{array}$ \\
\hline reduction \\
\hline $\begin{array}{l}\text { reminders } \\
\text { instructions }\end{array}$ \\
\hline $\begin{array}{l}\text { guiding avatar } \\
\text { implementation intentio }\end{array}$ \\
\hline $\begin{array}{l}\text { SOCIAL INTERACTIO } \\
\text { social support } \\
\text { cooperation } \\
\text { social identification }\end{array}$ \\
\hline $\begin{array}{l}\text { social comparison } \\
\text { social competition }\end{array}$ \\
\hline $\begin{array}{l}\text { INCENTIVISATION } \\
\text { praise } \\
\text { monetary rewards }\end{array}$ \\
\hline $\begin{array}{l}\text { complimentary rewards } \\
\text { recognition } \\
\text { game }\end{array}$ \\
\hline
\end{tabular}

indicating the progress in achieving goals

tracking extra information or comments, like a diary, in order to discuss later on with a coach

helping to gain insights into your situation and progress by seeing figures and graphs

showing results from sensors automatically in the application

setting your own goals

suggesting health goals that can be started automatically

$[22],[30]$

[22]

achieving a goal with step by step guidance, e.g., show every day what your tasks are for that day

minimising the efforts for completing a task, e.g., map route nearby when a distance is given

receiving reminders for achieving your set goals

receiving guided explanation about a specific goal, e.g., tutorial, movie, of help-pages

showing a virtual companion who can guide you through the application

planning activities in an online calendar

encouraging messages from friends and family

collaboration with friends to achieve challenges and common goals

[22], [30]

[22]

testimonials from users about how they interacted and experiences using the application

figures and graphs to compare yourself to other users

challenges among friends to achieve goals as soon as possible

22]

[22], [30] receiving motivational and appreciating messages while using the application [22] receiving points when achieving goals, these points can be used to buy rewards

receiving a medal when achieving a goal

sharing progress with others, optionally on social media

playing a game after completing a questionnaire or fulfilling a goal, e.g., bingo or puzzle

\subsection{Mobile device proficiency (MDP)}

The average score on MDP was 15.19 (SD=10.27), out of a possible score between 8 and 40 . However, the majority of participants had little to no experience 
Table 3. Factor analysis for motivation scale: intrinsic motivation (INT), extrinsic motivation (EXT), and amotivation (AMO).

\begin{tabular}{rccc}
\hline item & C1 & C2 & C3 \\
\hline INT5 & $\mathbf{0 . 8 7}$ & 0.20 & -0.03 \\
INT4 & $\mathbf{0 . 8 7}$ & -0.04 & -0.07 \\
INT2 & $\mathbf{0 . 6 7}$ & 0.11 & -0.09 \\
INT3 & $\mathbf{0 . 6 7}$ & 0.04 & -0.22 \\
\hline EXT1 & 0.01 & $\mathbf{0 . 8 2}$ & -0.20 \\
EXT2 & 0.13 & $\mathbf{0 . 7 1}$ & -0.06 \\
EXT3 & 0.21 & $\mathbf{0 . 7 0}$ & 0.07 \\
EXT4 & 0.00 & $\mathbf{0 . 4 0}$ & 0.11 \\
\hline AM03 & -0.17 & 0.25 & $\mathbf{0 . 8 0}$ \\
INT1 & 0.37 & 0.25 & $-\mathbf{0 . 6 4}$ \\
AMO2 & -0.38 & -0.18 & $\mathbf{0 . 5 7}$ \\
AM04 & 0.13 & -0.03 & $\mathbf{0 . 4 7}$ \\
AM01 & -0.19 & 0.32 & $\mathbf{0 . 4 6}$ \\
\hline Cronbach's alpha & 0.85 & 0.74 & 0.72 \\
\hline
\end{tabular}

in using mobile devices. The score of our sample was 'zero-inflated' as 26 participants scored 8 (the lowest possible score), thus indicating they never used a mobile device at all. At the same time, some participants were highly proficient. A histogram is shown in figure 1.

In order to divide participants into two groups: low and high MDP, a cut-off value to classify the participants was searched for in the results from a previous study by Roque and Boot [71] with 109 participants. In this study, on average, participants scored MDP=19.2 [71], which was then used as a cutoff value to classify participants into a low (MDP< 19.2) or high (MDP> 19.2) group. Applying this to our results indicated that 13 participants had an MDP score higher than 19.2 and were classified as 'high' (mean $=29.66, \mathrm{SD}=6.56)$, whereas 32 participants scored 'low' (mean=9.31, SD=3.10).

\subsection{RQ1. What are the preferences of older adults towards different motivational design techniques?}

Participants were asked to rate 32 different MDT on a scale from -3 to +3 . As aforementioned, a 0 indicated a neutral score, explained as "the application would not be better or worse if this technique were implemented", a positive score implied the SMHS would be evaluated as better because of the MDT, a negative score implied the app would be evaluated as worse because of the included MDT.

Table 4 presents a detailed account of all MDT, clustered by category, starting with the overall most favoured category.

Information. This category encompasses all MDT related to educating or informing participants of the

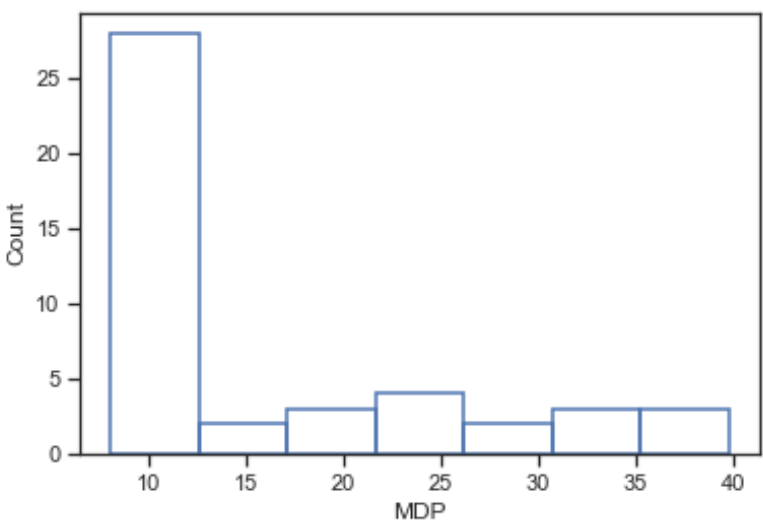

Figure 1. Histogram mobile device proficiency for all 45 participants. Minimum score of 8 corresponds with 'never tried' anything on a mobile device, the maximum score of 40 corresponds with answering all statements with 'very easily' to use a mobile device.

importance of health-related behaviour (see figure 2). Providing information was, overall, the most welcomed category by participants. All MDT in this category scored high on preference by participants, with average scores ranging from 1.60 to 2.29 on the +3 to -3 Likert scale. Participants welcomed both information tailored to their individual person (micro-tailoring, $M=2.29$, $S D=1.12$ ), as well as more general information on how to maintain a healthy lifestyle (health education, $M=2.11, S D=1.15)$ or information direct at the specific target group (macro-tailoring, $M=1.67$, $S D=1.21)$. Participants also welcomed information on simulated effects of negative life choices (fear appeal, $M=1.91, S D=1.14)$ and positive lifestyle choices (simulation, $M=1.60, S D=1.19$ ).

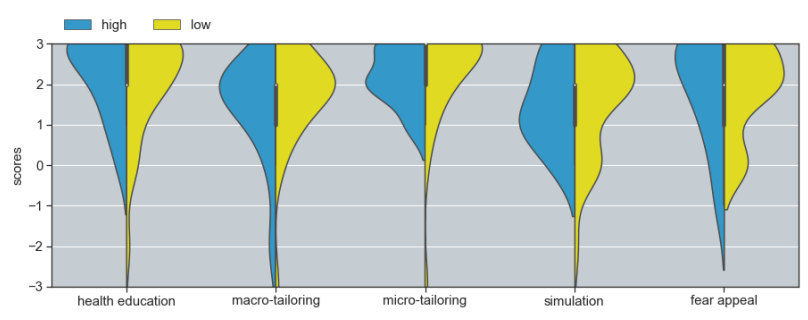

Figure 2. Motivational design techniques regarding information.

However, from the interviews, it became apparent that regarding fear appeal, some participants indicated possible negative consequences as this MDT could be experienced as punishing.

fear appeal: "That gives me the feeling that one is being reprimanded." - woman aged 73 
Table 4. Preference scores of motivational design techniques.

\begin{tabular}{|c|c|c|}
\hline motivational design technique & mean & SD \\
\hline INFORMATION & 1.92 & 0.87 \\
\hline micro-tailoring & 2.29 & 1.12 \\
\hline health education & 2.11 & 1.15 \\
\hline fear appeal & 1.91 & 1.14 \\
\hline macro-tailoring & 1.67 & 1.21 \\
\hline simulation & 1.60 & 1.19 \\
\hline TRUSTWORTHINESS \& LIKING & 1.68 & 0.79 \\
\hline surface credibility & 2.33 & 1.09 \\
\hline personalisation & 1.58 & 1.20 \\
\hline expertise & 1.47 & 1.29 \\
\hline verifiability & 1.33 & 1.24 \\
\hline AWARENESS \& PERSONAL INSIGHTS & 1.32 & 0.85 \\
\hline $\begin{array}{rr}\text { progress }\end{array}$ & 1.98 & 1.03 \\
\hline logging & 1.47 & 1.32 \\
\hline self-monitoring & 1.33 & 1.24 \\
\hline tracking & 1.33 & 1.17 \\
\hline self-goal setting & 1.09 & 1.06 \\
\hline automatic goal setting & 0.73 & 1.47 \\
\hline ABILITY & 1.02 & 0.80 \\
\hline rehearsal & 1.40 & 1.29 \\
\hline tunneling & 1.36 & 1.15 \\
\hline reduction & 1.13 & 1.27 \\
\hline reminders & 1.02 & 1.27 \\
\hline instructions & 0.98 & 1.25 \\
\hline guiding avatar & 0.78 & 1.26 \\
\hline implementation intention & 0.44 & 0.81 \\
\hline SOCIAL INTERACTIONS & 0.44 & 0.79 \\
\hline social support & 1.22 & 1.62 \\
\hline cooperation & 0.71 & 1.20 \\
\hline social identification & 0.49 & 1.06 \\
\hline social comparison & 0.18 & 1.37 \\
\hline social competition & -0.42 & 1.47 \\
\hline INCENTIVISATION & 0.16 & 0.76 \\
\hline $\begin{array}{l}\text { praise } \\
\text { p }\end{array}$ & 1.27 & 1.32 \\
\hline monetary rewards & 0.73 & 1.18 \\
\hline complimentary rewards & 0.00 & 1.40 \\
\hline recognition & -0.22 & 1.49 \\
\hline game & -0.98 & 1.60 \\
\hline
\end{tabular}

Regarding macro-tailored information, older adults also remarked this could be experienced as normative; while belonging to the same subgroup, e.g., gender or age category, everyone is still different.

macro-tailoring: "My situation is not the same as the situation of someone else." - man aged 73

macro-tailoring: "Nothing is obligatory, getting enough rest and care are the only things that still matter." - man aged 83
Trustworthiness \& Liking. This category encompasses all MDT that can increase credibility among users and allow them to tweak the app to their liking (see figure 3 ). These MDT were welcomed as well by participants, with average scores ranging from 1.33 to 2.33. Avoiding advertisements within an SMHS was found most important (surface credibility, $M=2.33, S D=1.09$ ), this scored highest among all MDT. Being able to set font sizes and colour schemes (personalisation, $M=$ $1.58, S D=1.20$ ) was also important for a majority of participants, as well as information on the experts who contributed to the design of the system (expertise, $M=1.47, S D=1.29$ ), and linking to scientific sources (verifiability, $M=1.33, S D=1.24$ ).

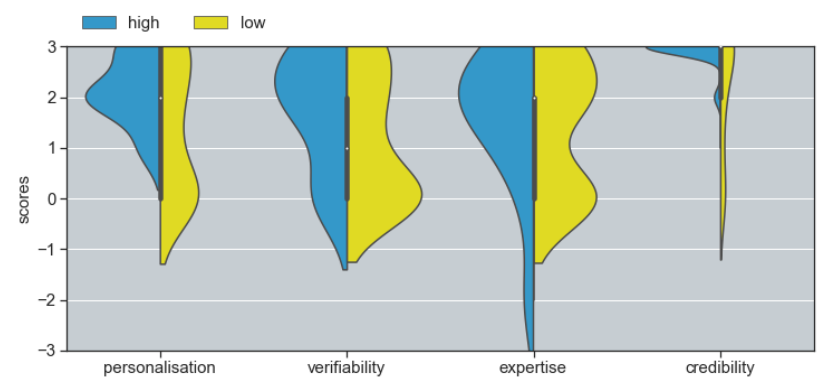

Figure 3. Motivational design techniques regarding trustworthiness \& liking.

Hence, participants thought it was not only important to know that the application was developed by specialists but also liked to find additional sources to confirm this.

verifiability: "You need to be able to take a look at this information, in order to check where it comes from." - man aged 73

Awareness \& Personal Insights. This category encompasses all MDT that help users gain insights or become more aware of their own health behaviour (see figure 4). Overall, these MDT were again perceived as relevant, with average scores ranging from 0.73 to 1.98 . Participants appreciated being able to monitor their progress (progress, $M=1.98, S D=1.03$ ), to be able to keep information in a diary (logging, $M=1.47, S D=1.32$ ), and monitor their stats from questionnaires and sensors (self-monitoring, $M=1.33, S D=1.24$, and tracking, $M=1.33, S D=1.17)$. Participants also liked the possibility to set their own goals (self-goal setting, $M=$ $1.09, S D=1.06$ ). While still positive, least favoured was the MDT where the system would suggest health goals automatically (automatic goal setting, $M=0.73$, $S D=1.47)$.

In their answers to the MDT of this category, participants again (as with information) indicated the importance of following their own pace and listening to their own body or a real-life coach. 


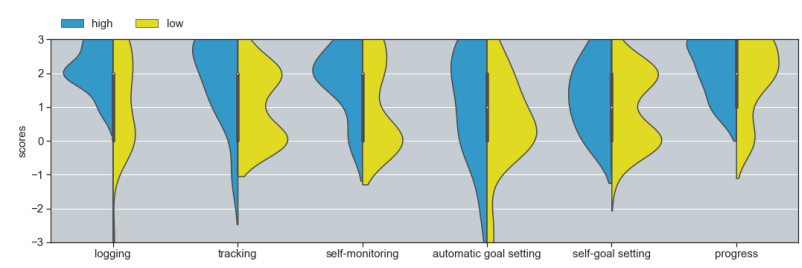

Figure 4. Motivational design techniques regarding awareness \& personal insights.

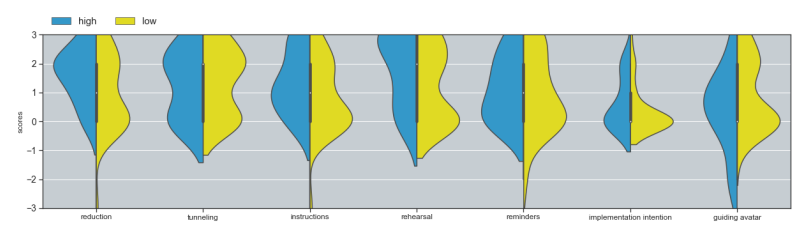

Figure 5. Motivational design techniques regarding ability.

logging: "I would deem it important to be followed up by the life coach (cf. caregiver in the institution)." - woman aged 78

automatic goal setting: "There are days that I feel like going for a walk and days I do not go for a walk, when I do not feel like it. Nobody should 'command' me." - man aged 85

Ability. This category encompasses all MDT that help participants to perform the actual health behaviour (see figure 5). On average, the MDT of this category scored positive. Nevertheless, with average scores ranging from 0.44 to 1.40 , this was less outspoken than the aforementioned categories. Participants welcomed MDT that would allow them to try out an activity first (rehearsal, $M=1.40, S D=1.29$ ), to be guided via a step-by-step approach (tunnelling, $M=1.36, S D=$ 1.15). Participants also welcomed support in the shape of smart calculations (reduction, $M=1.13, S D=1.27$ ) or receiving reminders (reminders, $M=1.02, S D=$ 1.27), and by means of instructions (instructions, $M=$ $.98, S D=1.25)$, possibly receiving guidance from a guiding avatar (guiding avatar, $M=.78, S D=1.26$ ). Finally, participants were also welcomed to plan activities ahead of time (implementation intention, $M=$ $.44, S D=.81$ ), yet scores are nuanced here.

From the answers provided by participants, it became apparent that participants appreciated being supported and guided in managing a healthy lifestyle. However, from their answers, we learned that they emphasised wanting to keep autonomy, and choose for themselves what they would or would not like to act upon instruction or reminder, depending on the situational context.

reminders: "I like to take decisions myself." man aged 85 tunneling: "I am 88 years old, that means that I cannot always do what I like to do." - man aged 88

implementation intention: "I no longer need a calendar. I do not plan anything ahead, I wait until the morning to see how I feel, and then I know whether or not I can do something in the afternoon." - man aged 83

Opinions on the use of a guiding avatar were divergent. While some participants thought this was a nice extra, others were less positive and thought it rather was artificial to use a virtual character.
guiding avatar: "I find that sympathetic, I also see this with 'Siri', who always wishes me a good night." - man aged 73
guiding avatar: "It remains a virtual super- visor, who will never be able to address me directly." - man aged 85

Social Interactions. This category encompasses all MDT that are related to interacting, comparing and sharing with peers, friends and family (see figure 6). The MDT of this category received divergent scores ranging from -.42 to 1.22 . Receiving encouraging messages from friends and family was welcomed (social support, $M=$ $1.22, S D=1.62)$, as was collaborating towards a shared goal (cooperation, $M=.71, S D=1.20$ ). Learning about other people's experiences by reading their testimonials were, on average, still valued (social identification, $M=$ $.49, S D=1.06)$. Comparing yourself to others received borderline scores (social comparison, $M=.18, S D=$ 1.37). Finally, competing with others through an SMHS scored negatively (social competition, $M=-.42, S D=$ 1.47).

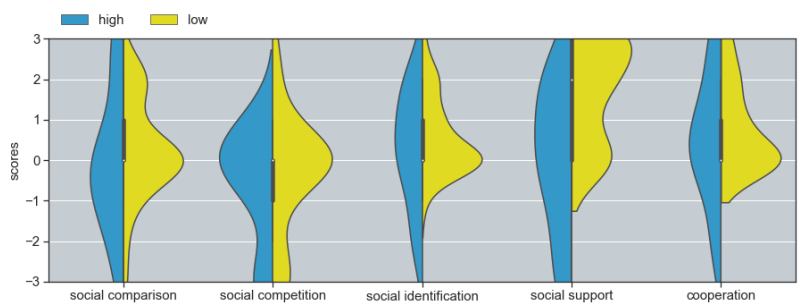

Figure 6. Motivational design techniques regarding social interactions.

The interviews uncovered that participants would appreciate messages from friends and family. MDT that encourage receiving motivational or inspirational messages, or collaborating with them would thus be appreciated. However, several participants also identified not wanting to burden anyone or were keen on their privacy and did not want to share a (virtual) space with their friends or family. 
cooperation: "Improve the mood through a sense of togetherness." - woman aged 80 cooperation: "Then I feel obliged, which is certainly not pleasant." - woman aged 79 social support: "No, that is my business, if you have to explain your story every time, people will tell: he is nagging again... That is not nice." - man aged 73

Participants emphasised, once more, the importance of following a healthy lifestyle for themselves, some of them also emphasising that they considered themselves as too old to participate in these MDT that focused on competition or comparing results with each other.

social competition: "We are at that age that we should stop chasing each other." - man aged 86 social competition: "That is no longer for me, on my old age." - man aged 84 social comparison: "Everyone is different." man aged 88

Incentivisation. This category encompasses all MDT that reinforce participants in their health behaviour through incentives, rewards, and praise (see figure 7). The MDT of this category received mixed sores, ranging from -.98 to 1.27 . Participants valued receiving encouraging messages through the SMHS (praise, $M=1.27, S D=1.32$ ). Participants also appreciated receiving vouchers or coupons to be real-life awarded (monetary rewards, $M=.73, S D=1.18$ ). However, participants were ambivalent towards receiving virtual medals or achievements (complimentary rewards, $M=$ $0, S D=1.40$ ), and on average, did not want to be able to share such successes with others, possibly via social media (recognition, $M=-.22, S D=1.49$ ) or be reward with mini-games such as a bingo or puzzle (game, $M=$ $-.98, S D=1.60)$.

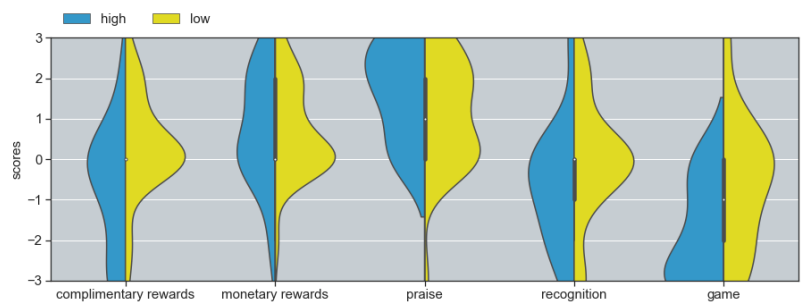

Figure 7. Motivational design techniques regarding incentivisation.

In their explanations, participants emphasised one last time that they would manage following a healthy lifestyle mainly for themselves, and not because of receiving points or rewards. Many participants felt this was rather childish and that it distracted them from the ultimate goal of self-managing their healthy lifestyle. If there would be an integrated game, participants found it important to be able to skip it. Also sharing healthrelated information was something participants were less keen on and preferred to limit to a physician.
recognition: "If this would say 'to my physician', I would say YES, but not through social media" - man aged 73
game: "I do not think that is important, then I would be distracted from what I was doing before." - woman aged 79
game: "I do not need games, no, I only need to reach my goal" - man aged 86
game: "That (cf. game) is not necessary, you have to do it on your own. That works for children, but not for us anymore." - woman aged 73
game: "But then you also need the option to skip it." - man aged 74

Nevertheless, some encouragements and genuine rewards were welcomed.

monetary rewards: "Yes, because I think that would be an extra motivation." - woman aged 78

praise: "I do like encouragements" - woman aged 78

\subsection{RQ2. Does motivation for health management mediate the preference towards motivational design techniques?}

In order to investigate this research question, a Spearman $(\rho)$ correlation $^{5}$ was performed to identify the relationship between the MDT and the participants' MHM, including intrinsic, extrinsic, and amotivation. Given that this is an exploratory study, we did not correct for any family-wise error rate (FWER); instead we chose to display confidence levels at the $95 \%$ level to inform readers ${ }^{6}$. Table 5 shows all correlation coefficients, all values that are considered significant at the .05 level (in black) are discussed below. Based on Field [83], correlation coefficients of \pm .3 represent a medium effect, whereas correlation coefficients of \pm .5 represent a large effect.

\footnotetext{
$\overline{{ }^{5} \text { The Spearman correlation coefficient is a non-parametric measure }}$ of the strength between two variables and is suitable for ordinal data [81].

${ }^{6}$ Although such an FWER correction would lower the change of Type I errors, it would, in turn, increase the chance of Type II errors, due to the small sample size and the expected moderate correlations, based on the previous studies [30]. Therefore, Spearman $(\rho)$ correlation coefficients along with a $95 \% \mathrm{CI}$ are reported instead [82].
} 
Table 5. Spearman correlations between results on motivation for health management, mobile device proficiency, and motivational design techniques.

\begin{tabular}{|c|c|c|c|c|}
\hline $\begin{array}{r}\text { motivational design technique } \\
\text { name }\end{array}$ & $\begin{array}{r}\text { intrinsic } \\
\rho[95 \% C I]\end{array}$ & $\begin{array}{r}\text { extrinsic } \\
\rho[95 \% C I]\end{array}$ & $\begin{array}{r}\text { amotivation } \\
\rho[95 \% C I]\end{array}$ & $\begin{array}{r}\text { mobile device proficiency } \\
\rho[95 \% C I]\end{array}$ \\
\hline $\begin{array}{r}\text { INFORMATION } \\
\text { micro-tailoring } \\
\text { health education } \\
\text { fear appeal } \\
\text { macro-tailoring } \\
\text { simulation }\end{array}$ & $\begin{array}{r}0.367[0.08,0.6] \\
0.363[0.08,0.59] \\
0.286[-0.01,0.53] \\
0.159[-0.14,0.43] \\
0.37[0.09,0.6] \\
0.148[-0.15,0.42]\end{array}$ & $\begin{array}{r}0.248[-0.05,0.51] \\
0.217[-0.08,0.48] \\
0.14[-0.16,0.42] \\
0.234[-0.06,0.49] \\
0.209[-0.09,0.47] \\
0.233[-0.07,0.49]\end{array}$ & $\begin{array}{r}-0.179[-0.45,0.12] \\
-0.411[-0.63,-0.13] \\
0.001[-0.29,0.29] \\
-0.008[-0.3,0.29] \\
-0.051[-0.34,0.25] \\
-0.067[-0.35,0.23]\end{array}$ & $\begin{array}{r}-0.108[-0.39,0.19] \\
-0.207[-0.47,0.09] \\
0.01[-0.28,0.3] \\
-0.039[-0.33,0.26] \\
-0.175[-0.45,0.12] \\
-0.028[-0.32,0.27]\end{array}$ \\
\hline $\begin{array}{r}\text { TRUSTWORTHINESS \& LIKING } \\
\text { surface credibility } \\
\text { personalisation } \\
\text { expertise } \\
\text { verifiability }\end{array}$ & $\begin{array}{r}0.312[0.02,0.55] \\
-0.097[-0.38,0.2] \\
-0.087[-0.37,0.21] \\
0.541[0.29,0.72] \\
0.424[0.15,0.64]\end{array}$ & $\begin{array}{r}0.169[-0.13,0.44] \\
-0.008[-0.3,0.29] \\
-0.078[-0.36,0.22] \\
0.322[0.03,0.56] \\
0.251[-0.05,0.51]\end{array}$ & $\begin{array}{r}-0.343[-0.58,-0.05] \\
-0.219[-0.48,0.08] \\
-0.221[-0.48,0.08] \\
-0.214[-0.48,0.09] \\
-0.241[-0.5,0.06]\end{array}$ & $\begin{array}{r}0.271[-0.02,0.52] \\
0.133[-0.17,0.41] \\
0.337[0.05,0.57] \\
0.1[-0.2,0.38] \\
0.122[-0.18,0.4]\end{array}$ \\
\hline $\begin{array}{r}\text { AWARENESS \& PERSONAL INSIGHTS } \\
\text { progress } \\
\text { logging } \\
\text { self-monitoring } \\
\text { tracking } \\
\text { self-goal setting } \\
\text { automatic goal setting }\end{array}$ & $\begin{array}{r}0.343[0.06,0.58] \\
0.091[-0.21,0.37] \\
0.18[-0.12,0.45] \\
0.388[0.11,0.61] \\
0.333[0.04,0.57] \\
0.217[-0.08,0.48] \\
0.194[-0.11,0.46]\end{array}$ & $\begin{array}{r}0.025[-0.27,0.32] \\
0.199[-0.1,0.47] \\
-0.012[-0.3,0.28] \\
0.1[-0.2,0.38] \\
-0.086[-0.37,0.21] \\
-0.091[-0.37,0.21] \\
0.106[-0.19,0.39]\end{array}$ & $\begin{array}{r}-0.194[-0.46,0.11] \\
-0.239[-0.5,0.06] \\
-0.037[-0.33,0.26] \\
-0.053[-0.34,0.24] \\
-0.178[-0.45,0.12] \\
-0.213[-0.48,0.09] \\
-0.108[-0.39,0.19]\end{array}$ & $\begin{array}{r}0.409[0.13,0.63] \\
0.193[-0.11,0.46] \\
0.341[0.05,0.58] \\
0.223[-0.08,0.48] \\
0.402[0.12,0.62] \\
0.209[-0.09,0.47] \\
0.256[-0.04,0.51]\end{array}$ \\
\hline $\begin{array}{r}\text { ABILITY } \\
\text { rehearsal } \\
\text { tunneling } \\
\text { reduction } \\
\text { reminders } \\
\text { instructions } \\
\text { guiding avatar } \\
\text { implementation intention }\end{array}$ & $\begin{array}{r}0.404[0.13,0.62] \\
0.163[-0.14,0.44] \\
0.243[-0.05,0.5] \\
0.274[-0.02,0.53] \\
0.477[0.21,0.68] \\
0.285[-0.01,0.53] \\
0.318[0.03,0.56] \\
0.044[-0.25,0.33]\end{array}$ & $\begin{array}{r}0.117[-0.18,0.4] \\
-0.138[-0.41,0.16] \\
0.249[-0.05,0.51] \\
0.03[-0.27,0.32] \\
0.186[-0.11,0.45] \\
0.0[-0.29,0.29] \\
0.06[-0.24,0.35] \\
0.182[-0.12,0.45]\end{array}$ & $\begin{array}{r}-0.21[-0.47,0.09] \\
-0.282[-0.53,0.01] \\
-0.016[-0.31,0.28] \\
-0.14[-0.42,0.16] \\
-0.043[-0.33,0.25] \\
-0.154[-0.43,0.15] \\
-0.225[-0.49,0.07] \\
-0.067[-0.35,0.23]\end{array}$ & $\begin{array}{r}0.131[-0.17,0.41] \\
0.217[-0.08,0.48] \\
-0.051[-0.34,0.25] \\
0.186[-0.11,0.46] \\
0.112[-0.19,0.39] \\
0.121[-0.18,0.4] \\
-0.022[-0.31,0.27] \\
0.217[-0.08,0.48]\end{array}$ \\
\hline $\begin{array}{r}\text { SOCIAL INTERACTIONS } \\
\text { social support } \\
\text { cooperation } \\
\text { social identification } \\
\text { social comparison } \\
\text { social competition }\end{array}$ & $\begin{array}{r}0.258[-0.04,0.51] \\
-0.013[-0.31,0.28] \\
0.244[-0.05,0.5] \\
0.21[-0.09,0.47] \\
0.031[-0.26,0.32] \\
0.224[-0.07,0.49]\end{array}$ & $\begin{array}{r}0.129[-0.17,0.41] \\
0.352[0.07,0.58] \\
0.146[-0.15,0.42] \\
-0.03[-0.32,0.27] \\
0.064[-0.23,0.35] \\
0.019[-0.28,0.31]\end{array}$ & $\begin{array}{r}0.037[-0.26,0.33] \\
0.187[-0.11,0.46] \\
-0.193[-0.46,0.11] \\
-0.094[-0.38,0.2] \\
-0.012[-0.3,0.28] \\
0.096[-0.2,0.38]\end{array}$ & $\begin{array}{r}-0.227[-0.49,0.07] \\
-0.413[-0.63,-0.14] \\
-0.117[-0.4,0.18] \\
-0.091[-0.37,0.21] \\
-0.074[-0.36,0.22] \\
-0.035[-0.33,0.26]\end{array}$ \\
\hline $\begin{array}{r}\text { INCENTIVISATION } \\
\text { praise } \\
\text { monetary rewards } \\
\text { complimentary rewards } \\
\text { recognition } \\
\text { game }\end{array}$ & $\begin{array}{r}0.079[-0.22,0.36] \\
0.025[-0.27,0.32] \\
-0.122[-0.4,0.18] \\
-0.107[-0.39,0.19] \\
-0.043[-0.33,0.25] \\
0.167[-0.13,0.44]\end{array}$ & $\begin{array}{r}0.248[-0.05,0.5] \\
0.114[-0.19,0.39] \\
0.07[-0.23,0.36] \\
0.202[-0.1,0.47] \\
0.04[-0.26,0.33] \\
0.164[-0.14,0.44]\end{array}$ & $\begin{array}{r}0.298[0.0,0.54] \\
0.127[-0.17,0.41] \\
0.248[-0.05,0.5] \\
0.295[0.0,0.54] \\
0.028[-0.27,0.32] \\
0.043[-0.25,0.33]\end{array}$ & $\begin{array}{r}-0.165[-0.44,0.14] \\
0.212[-0.09,0.48] \\
0.064[-0.23,0.35] \\
-0.313[-0.56,-0.02] \\
-0.101[-0.38,0.2] \\
-0.278[-0.53,0.02]\end{array}$ \\
\hline
\end{tabular}

Information. On average, MDT within this category correlate moderate $( \pm .3)$ with intrinsic motivation $(\rho=$ .367). In total, it comprises three correlations between specific MDT and the different levels of motivation that score at least moderate; more specifically macrotailoring $(\rho=.370)$ and micro-tailoring $(\rho=.363)$ have a moderate correlation with intrinsic motivation, and additionally, micro-tailoring also has a large, negative $(\rho=-.411)$ correlation with amotivation.

Trustworthiness \& Liking. On average, MDT within this category correlate moderate $( \pm .3)$ with both intrinsic motivation $(\rho=.312)$ and, although negative, with amotivation $(\rho=-.343)$. In total, it comprises three correlations between MDT and the different levels of motivation that score at least moderately. Both expertise $(\rho=.541)$ and verifiability $(\rho=.424)$ have respectively a strong and large correlation with intrinsic motivation. Additionally, expertise also shows a moderate correlation with extrinsic motivation $(\rho=$ $.322)$.

Awareness \& Personal Insights. On average, MDT within this category correlate moderate $( \pm .3)$ with intrinsic motivation $(\rho=.343)$. In total, it comprises two correlations between MDT and the different levels of motivation that score at least moderately. In particular, self-monitoring $(\rho=.388)$ and tracking $(\rho=$ .333) correlate moderately with intrinsic motivation. 
Ability. On average, MDT within this category correlate moderate $( \pm .3)$ with intrinsic motivation $(\rho=.404)$. In total, it comprises two MDT and the different levels of motivation that score at least moderately. In particular, reminders $(\rho=.477)$ and guiding avatars $(\rho=$ .318) correlate respectively large and moderately with intrinsic motivation.

Social Interactions. On average, MDT within this category correlate weak $(\leq .3)$ with the different types of motivation. In total, it comprises only one correlation that scores at least moderately, i.e., between social support and extrinsic motivation $(\rho=.352)$.

Incentivisation. On average, MDT within this category correlate moderately $( \pm .3)$ with amotivation $(\rho=.298)$. In total, it comprises no moderate to strong correlations between MDT and any of the different levels of motivation.

\subsection{RQ3. Does mobile device proficiency mediate the preference towards motivational design techniques?}

Similar to the previous research question, a Spearman $(\rho)$ correlation $^{5}$ was performed between MDP and preferences for MDT. Results are displayed in table 5. Afterwards, participants' scores for MDP were categorised as low $(\mathrm{MDP} \leq 19.2)$ or high $(\mathrm{MDP}>19.2)$ and analysed based on violin plots that were split on the level of MDP. Below results for each category will be discussed.

Information. No moderate correlations can be found in this category. However, most items tend to have a weak and negative correlation with MDP, suggesting that the more experienced with mobile devices, the less interested in these techniques.

Figure 2 shows mainly positively skewed distributions, indicating that accessing relevant information sources seems to be important for both participants with high and low MDP.

Trustworthiness \& Liking. On average, MDT within this category correlate weakly $(\leq .3)$ with $\operatorname{MDP}(\rho=.271)$. In total, it comprises one moderate correlation between personalisation $(\rho=.337)$ and MDP, which was thus more preferred by those with a higher MDP.

Figure 3 indicates that overall, participants all had a positive score for these techniques. However, it can also be noted that participants with low MDP often scored either neutral or positive towards the MDT.

Awareness \& Personal Insights. On average, MDT within this category correlate moderately $( \pm .3)$ with $\operatorname{MDP}(\rho=$ .409). In total, it comprises three moderate correlations with MDP; tracking $(\rho=.402)$, logging $(\rho=.341)$, and automatic goal setting $(\rho=.256)$ would then be preferred.
According to figure 4, it is clear that participants with a high MDP were mostly positive towards the different MDT. Participants with a low MDP again often scored neutral, but also showed some preferences for tracking, self-goal setting, and progress.

Ability. On average, MDT within this category do not seem to correlate with $\operatorname{MDP}(\rho=.131)$; none of the specific MDT showed a correlation with MDP representing at least a medium effect.

When inspecting the results in figure 5, participants with a high MDP showed more positive skewed distributions, while participants with a low MDP often scored more neutral.

Social Interactions. On average, MDT within this category showed a negative but weak $(\leq .3)$ correlation with MDP $(\rho=-.227)$. In total, it comprises only one moderate and negative correlation with MDP, social support $(\rho=-.413)$. However, for this category, all underlying MDT seem to correlate negative, although weak. This could indicate that participants with a high MDP would dislike having these MDT implemented.

When investigating figure 6, results of participants with a low MDP are again more distributed around zero, whereas the other participants show more widespread results. Social support and social comparison indicate a higher preference for participants without any experience than those with a high MDP.

Incentivisation. On average, MDT within this category showed a negative but weak $(\leq .3)$ correlation with MDP $(\rho=-.165)$. In total, it comprises only one moderate and negative correlation with MDP, complimentary rewards $(\rho=-.313)$.

Figure 7 shows that results are more spread for participants with a high MDP than those with a low MDP. Participants with less experience again more often scored neutral to the different techniques, whereas participants with a high MDP showed, except for monetary rewards and praise, show rather negatively skewed distributions.

Influence of high versus low mobile device proficiency on preference towards motivational design techniques. A MannWhitney $U$ test was conducted for every category to observe these differences between participants with high and low MDP. Awareness \& personal insights did show a significant difference $(U=310.0, p=.005)$; participants with a high $\operatorname{MDP}($ mean $=1.81, \mathrm{SD}=.719)$ tend to have a higher preference for these MDT than participants with a low MDP (mean=1.13, SD=.825). Also trustworthiness \& liking showed a significant difference $(U=303.5, p=.008)$ between participants with a high $\operatorname{MDP}($ mean=2.12, $\mathrm{SD}=.574)$ and those with a low MDP (mean=1.50, $\mathrm{SD}=.798$ ). No significant differences were found for ability $(U=250.5, p=.146)$, information $(U=183.5, p=.736)$, incentivisation $(U=$ 
$125.5, p=.983)$, and social interactions $(U=142.0, p=$ .953).

From the violin plots, it was also observed that participants with a low MDP more often scored neutral compared to those with a high MDP. In order to verify this observation, a joint plot was generated. Figure 8 visualises a joint plot between the individual scores on all MDT, and the according MDP scores. Across the $\mathrm{x}$ - or $\mathrm{y}$-axis, the distribution for respectively MDT scores and MDP are visualised. The hexagons show all answers, whereas a darker colour indicates more similar responses. On the one hand, this figure shows that scores for MDT have a positively skewed distribution. On the other hand, the dark hexagons at the bottom left quadrant indicate that participants with no or very low MDP tend to score most often neutral or positive. Moreover, a Chi-Square test was performed to investigate whether there was, in general over all MDT, a difference between MDP (low or high) and scoring (neutral or other). A statistically significant association was found between MDP and scoring $\chi^{2}(1)=36.8, p=$ 0 .

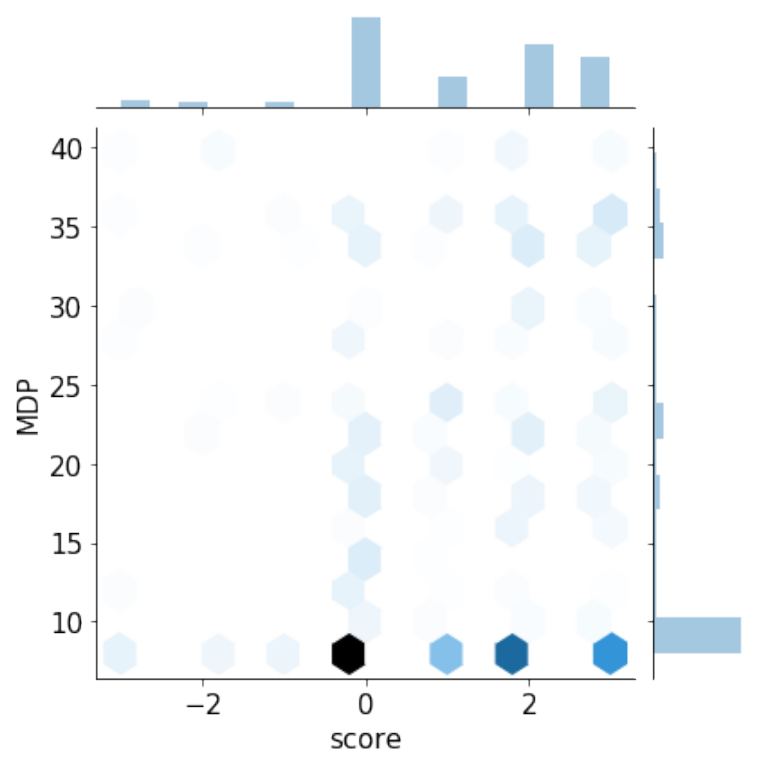

Figure 8. Joint plot between individual scores on all motivational design techniques and the score on the mobile device proficiency questionnaires.

\section{Discussion}

In this study, we interviewed 45 older adults, with an average age of 84 , regarding their preferences for 32 different MDT, embedded in interactive systems to self-manage health. Besides, we polled for levels of intrinsic, extrinsic and amotivation for self-managing health, their technological proficiency and investigated associations with preferences for MDT. In the paragraphs below, we first reflect on the different research questions and relate them to earlier work. We end with formulating implications for the design of SMHS for older adults and suggest avenues for future research.

\subsection{Revisiting the search questions}

RQ1. What are the preferences of older adults towards different motivational design techniques?. Concerning the first research question, we found that, on average, older adults welcomed MDT; 28 out of 32 MDT received a positive score. However, the scores also show large standard deviations, reflecting the heterogeneity among participants. This observation is further unpacked in section 6.2.

Based on our findings, MDT that provide information on managing health, tailored to the older adult, were most preferred. Next, older adults also welcomed MDT that increase overall trustworthiness and liking of the application. MDT that increase awareness and provide them with the ability to managing their health were also valued. Somewhat less favoured were techniques that focus on social comparisons or competitions with friends and families. Least liked were techniques that favour virtual incentives, sharing (successes) through social media or being rewarded with mini-games.

These exploratory findings are in line with findings by Geuens et al. [55] who also found social support and incentivisation to score least among MDT, whereas techniques related to information, ability, awareness and trustworthiness were much liked. Altmeyer et al. [28] also found virtual rewards such as badges and points as least preferred, but did found social techniques scoring well. These findings are also not entirely in line with the results from van Velsen et al. [30]. Moreover, in our study, overall appreciation towards the MDT scored higher compared to van Velsen et al. [30].

RQ2. Does motivation for self-management of health mediate the preference towards motivational design techniques?. Results suggest that older adults are motivated to selfmanage their health. Participants scored positive on both intrinsic and extrinsic motivation, and negative on amotivation. Compared to other studies [30, 32], it is remarkable that participants in our study scored equally high on extrinsic levels of motivation as intrinsic levels of motivation.

Based on our study's findings, intrinsic motivation is at least moderately correlated with four out of six categories, i.e., information, trustworthiness \& liking, awareness \& personal insight, and ability. Intrinsic motivation is correlated with providing health information in general, and in particular, with providing personalised and tailored health information. Intrinsic motivation is also related to increasing 
trustworthiness \& liking, and in particular by unveiling experts and highlighting credible sources. Intrinsic motivation is also correlated with increasing awareness \& personal insights, in particular through selfmonitoring and tracking. Finally, intrinsic motivation is correlated with supporting ability and, in particular, by providing reminders and offering a guiding avatar. Extrinsic motivation, instead, only has a moderate correlation with showing experts behind the application and allowing friends and family to send encouraging messages. Amotivation had a moderate positive correlation with incentivisation, in general, and correlated moderately and negative with offering personalised information and reinforcing trustworthiness \& liking.

These correlations are in line with literature on intrinsic versus extrinsic motivation and healthrelated behaviour [62, 72]. As suggested by [84], participants who are intrinsically motivated will value MDT supporting their specific health-related actions and increasing insights. Participants who are more extrinsically motivated value encouragement and backup from experts. Finally, those that are amotivated overall do not favour MDT. However, unlike van Velsen et al. [30], we found not all MDT had a positive relationship with intrinsic or extrinsic motivation.

RQ3. Does mobile device proficiency mediate the preference towards motivational design techniques?. When assessing MDP, the majority $(n=32)$ of the participants had little to no experience; only 13 participants had used either a smartphone or tablet. We found that MDP correlated to personalisation, as well as being able to $\log$ and track. MDP was negatively correlated to receiving encouraging messages through an SMHS (social support) or the offering of virtual rewards and badges (complimentary rewards). However, further analysis showed that those scoring low in MDP more often choose to score an MDT as neutral; this observation is discussed in the limitations.

\subsection{Motivational design techniques - one size does not fit all}

While scores of MDT were overall positive, caution is needed; the scores also showed large standard deviations, reflecting the heterogeneity among participants in how MDT were perceived. Concerning gamification, van Roy et al. [85] have detailed how even one badge can be assigned nine different functionalisations, i.e., meanings, from status markers to contingent rewards, depending on user characteristics and situational context [85]. These different functionalisations impact experience, motivation and behaviour. In this study, participants spanned a wide range of age, gender, living arrangements, education, and life history. Recognising a life span perspective, as noted by Vines et al. [86], citing Bond et al. [87]: "Rather than growing more alike as we age, we become more unique." [87]. This heterogeneity of the older population group has already been confirmed in previous studies, as well as its impact on attitudes towards health-related technologies, e.g., $[11,12,88,89]$. Hence, it needs to be acknowledged that the same MDT can hold radically different meanings for different older adults, or even the same older adult, over time.

Through the interviews, we understood that some participants perceived themselves as 'too old' for using these techniques. These older adults often still scored preferences for MDT neutral, yet hinted that these MDT were not for them anymore, i.e., "I will do it my way" as a woman aged 91 often stated. Besides, some participants also mentioned that they were just not interested in these MDT. As earlier work indicated, perceived usefulness is one of the main barriers for technology adoption in older adults [12, 90]. Taken this into account, it will remain difficult to persuade participants who are amotivated to self-manage health to use an SMHS in the first place $[30,32]$.

Participants interested in using an SMHS and favoured MDT, emphasised the importance of managing their health for themselves and the need to recognise that every older adult is unique; in their selfmanagement trajectory. Moreover, participants noted this trajectory is unpredictable, even for them. They had to "take each day as it comes". This may explain why participants, while overall liking MDT related to ability and awareness, liked least those MDT such as automatic goal setting or implementation intentions. From older adults' explanations, it was understood that such MDT were oftentimes perceived as undermining their autonomy. This may also explain why participants disliked social competition or comparisons, as every person's situation is unique. Such MDT could set expectations that they might not be able to meet and should, therefore, be treated carefully. This is in line with earlier work from Geuens et al. [55] who stated that in applications for chronic disease management, MDT that target social interaction or provide incentives actually lower motivation of patients to use the application, as "every patient hurts in their own way" [55]. In our study as well, it was found that participants highly valued their autonomy, one of the primary drivers for intrinsic motivation [91], and needed MDT to respect and reflect this uniqueness.

\subsection{Implications for design}

For designers of SMHS, this study yields insights into which and how MDT are worth implementing in SMHS for older adults. Based on the results, (1) providing information on how to manage a healthy lifestyle was valued by most participants. Especially 
if it could be (2) tailored information, but with respect for the individual. Besides, users should be able to inspect and (3) verify the designers' expertise or content within the application. Designers should acknowledge the heterogeneity among older adults, and MDT should (4) keep the life span perspective of the user in mind. When implementing MDT, it is therefore important to (5) ensure that the techniques are not intrusive. Techniques (6) targeting stringent and normative frames should be avoided, e.g., taking 10.000 steps a day. Consequently, (7) the user should always have the autonomy to choose their own goals. Participants need to follow their own pace and see how they feel, thus listening to their bodies. For this reason, (8) selecting goals should also be made flexible and adaptive from day to day.

Receiving social support was valued by the participants. However, they should again be (9) given sufficient autonomy to choose how their (care) network interacts with the application, e.g., receiving motivational messages was found pleasant. However, they did not want to burden their loved ones with results available in the SMHS; this was rather for physicians or caregivers. Social interactions that arise from (10) comparisons or competition should be avoided; every older adult is unique in their management of health and well-being. Besides support, older adults also (11) valued instructions, or a guiding avatar to help them through the application. Also, (12) being able to personalise the application was valued by older adults. However, they are (13) not eager for mini-games to be part in SMHS, and at least would want to be able to skip these. Finally, (14) advertisements should be avoided at all costs, as this was overall, the most important MDT.

\section{Limitations and future work}

We observed that an interviewer was needed to assist in filling out the questionnaires. However, the presence of this interviewer may have introduced bias in the answers of older adults.

Additionally, in this study, we wanted to investigate how to design an SMHS for older adults. Therefore, we tested which design techniques participants would welcome and which not. In this regard, it was clearly mentioned that participants could score 'neutral' (score $=0)$ if inclusion of the MDT would neither make the application better nor worse. When analysing the results, we observed that participants often gave 'neutral' scores, most often by those who scored low on MDP. Therefore, these zero-scores may reflect a limited understanding of the MDT rather than an actual neutral scoring. In order to further scrutinise attitudes, indepth interviews are needed.

Finally, although the MDP questionnaire was selected with the greatest care as a questionnaire specifically geared towards mobile device proficiency and validated with older adults, still, for the sample of oldest older adults in our sample, we likely hit a floor effect, resulting in zero-inflated data. We recommend future research to investigate technological proficiency further, perhaps also focusing on anxieties towards novel technologies [92-94].

\section{Conclusion}

In this study, a user evaluation with 45 participants was conducted to understand which MDT older adults would appreciate in SMHS. The user evaluation was conducted based on questionnaires polling for the personal motivation of self-managing their health, a questionnaire polling for their experience in mobile device proficiency, and a questionnaire polling for their preference towards 32 different MDT. During the questionnaires, participants were encouraged to support their answers. This exploratory research study investigated (1) preferences of older adults towards different MDT, (2) motivation for self-management of health mediating the preference towards MDT, and (3) MDP mediating the preference towards different MDT in SMHS. Especially techniques related to information, trustworthiness \& liking, and awareness \& personal insights portray a bright future. However, older adults are a heterogeneous group and thus call for being able to tailor the techniques to the wishes of the individual. Moreover, these MDT are no panacea; participants who are not motivated to self-manage a healthy lifestyle would probably also not benefit from any of these techniques. It was also noteworthy that most participants had little MDP and, in addition, also scored more 'neutral' towards MDT. After answering the different research questions and relating these to earlier work, implications for design were presented to help future designers of SMHS in making informed decisions on which MDT they would (not) want to include in their SMHS. However, this study's limitations necessitate further research, e.g., a hands-on adoption study, to let older adults gain salient experiences and make sure that they can make an informed decision. These further research studies are essential in order to validate, clarify, and extend our findings.

\section{Acknowledgement}

We would like to thank Triamant [79] for their cooperation, as well as all participants who agreed on conducting this research study.

This research did not receive any specific grant from funding agencies in the public, commercial, or not-forprofit sectors. 


\section{References}

[1] Doyle, J., O’Mullane, B., McGee, S. and Knapp, R.B. (2012) YourWellness: designing an application to support positive emotional wellbeing in older adults. In Proceedings of the 26th Annual BCS Interaction Specialist Group Conference on People and Computers (http://dl.acm.org/citation.cfm?id=2377942: British Computer Society): 221-226. URL http: //dl . acm.org/ citation. cfm?id=2377942.

[2] Jiménez-Mixco, V., Cabrera-Umpiérrez, M.F., Blanco, A.E., Waldmeyer, M.T.A., Tantinger, D. and Bonfiglio, S. (2012) Personalized e-health for elderly self-care and empowerment. In Ambient Intelligence-Software and Applications (Springer), 213-216.

[3] JAschinski, C. (2014) Ambient Assisted Living: Towards a Model of Technology Adoption and Use Among Elderly Users. In Proceedings of the 2014 ACM International Joint Conference on Pervasive and Ubiquitous Computing: Adjunct Publication, UbiComp '14 Adjunct (New York, NY, USA: ACM): 319-324. doi:10.1145/2638728.2638838, URL http: / / doi .acm.org/10.1145/2638728.2638838.

[4] VAN Hoof, C. (2013) Addressing the healthcare cost dilemma by managing health instead of managing illness an opportunity for wireless wearable sensors. In 5th IEEE International Workshop on Advances in Sensors and Interfaces IWASI (https://doi.org/10.7873/DATE.2013.312: IEEE): 99. doi:10.1109/IWASI.2013.6576064.

[5] Verdezoto, N. and Grönvall, E. (2016) On preventive blood pressure self-monitoring at home. Cognition, Technology \& Work 18(2): 267-285. doi:10.1007/s10111-0150358-7, URL https://link.springer.com/article/ 10. 1007/s10111-015-0358-7.

[6] Doyle, J., Walsh, L., Sassu, A. and McDonagh, T. (2014) Designing a Wellness Self-management Tool for Older Adults: Results from a Field Trial of YourWellness. In Proceedings of the 8th International Conference on Pervasive Computing Technologies for Healthcare, PervasiveHealth '14 (ICST, Brussels, Belgium, Belgium: ICST (Institute for Computer Sciences, Social-Informatics and Telecommunications Engineering)): 134141. doi:10.4108/icst.pervasivehealth.2014.254950, URL http://dx.doi.org/10.4108/icst. pervasivehealth.2014.254950.

[7] Jiménez-Mixco, V., Cabrera-Umpiérrez, M.F., Arrendondo, M.T., Panou, M., Struck, M. and Bonfiglio, S. (2013) Feasibility of a wireless health monitoring system for prevention and health assessment of elderly people. In 2013 35th Annual International Conference of the IEEE Engineering in Medicine and Biology Society (EMBC) (Osaka, Japan: IEEE): 7306-7309.

[8] Doyle, J., Caprani, N. and Bond, R. (2015) Older adults' attitudes to self-management of health and wellness through smart home data. In 2015 9th International Conference on Pervasive Computing Technologies for Healthcare (PervasiveHealth) (https://ieeexplore.ieee.org/stamp/stamp.jsp?arnumber=7349388Management 35(4): 419-431.

IEEE): 129-136. doi:10.4108/icst.pervasivehealth.2015.259279.
[9] D’Haeseleer, I., Oeyen, D., Vanrumste, B., Schreurs, D. and Vanden Abeele, V. (2020) The unacceptance of a self-management health system by healthy older adults. In ICT 4AWE: 269-280.

[10] Heart, T. and Kalderon, E. (2013) Older adults: Are they ready to adopt health-related ICT? International Journal of Medical Informatics 82(11): e209-e231. doi:10.1016/j.ijmedinf.2011.03.002, URL http://www.sciencedirect.com/science/article/ pii/S1386505611000682.

[11] Peek, S.T., Luijkx, K.G., Rijnaard, M.D., Nieboer, M.E., van der Voort, C.S., AArts, S., van Hoof, J. et al. (2016) Older adults' reasons for using technology while aging in place. Gerontology 62(2): 226-237.

[12] D’Haeseleer, I., Gerling, K., Schreurs, D., Vanrumste, B. and Vanden Abeele, V. (2019) Ageing is not a disease: Pitfalls for the acceptance of self-management health systems supporting healthy ageing. In The 21st International ACM SIGACCESS Conference on Computers and Accessibility (ACM): 286-298.

[13] Kononova, A., Li, L., Kamp, K., Bowen, M., Rikard, R., Cotten, S. and Peng, W. (2019) The use of wearable activity trackers among older adults: Focus group study of tracker perceptions, motivators, and barriers in the maintenance stage of behavior change. JMIR mHealth and uHealth 7(4): e9832.

[14] Wang, S., Bolling, K., Mao, W., Reichstadt, J., Jeste, D., Kim, H.C. and NebeKer, C. (2019) Technology to support aging in place: older adults' perspectives. In Healthcare (Multidisciplinary Digital Publishing Institute), 7: 60.

[15] Vaportzis, E., Giatsi Clausen, M. and Gow, A.J. (2017) Older adults perceptions of technology and barriers to interacting with tablet computers: a focus group study. Frontiers in psychology 8: 1687.

[16] Yusif, S., Soar, J. and Hafeez-Baig, A. (2016) Older people, assistive technologies, and the barriers to adoption: A systematic review. International journal of medical informatics 94: 112-116.

[17] Knowles, B. and Hanson, V.L. (2018) Older adults' deployment of 'distrust'. ACM Transactions on Computer-Human Interaction (TOCHI) 25(4): 21:1-21:25. doi:10.1145/3196490, URL http: // doi .acm.org/10.1145/3196490.

[18] Keller, J.M. (2010) Motivational Design for Learning and Performance (Boston, MA: Springer US), chap. What is Motivational Design?, 2141. doi:10.1007/978-1-4419-1250-3_2, URL https: / / doi.org/10.1007/978-1-4419-1250-3_2.

[19] Oinas-Kukkonen, H. and Harjumaa, M. (2009) Persuasive systems design: Key issues, process model, and system features. Communications of the Association for Information Systems 24(1): 28.

[20] Deterding, S., Dixon, D., Khaled, R. and Nacke, L. (2011) From game design elements to gamefulness: defining gamification. In Proceedings of the 15th international academic MindTrek conference: Envisioning future media environments: 9-15.

[21] Hamari, J. and Koivisto, J. (2015) Why do people use gamification services? International Journal of Information 
[22] Geuens, J., Geurts, L., Gerling, K., De Croon, R. and Abeele, V.V. (2019) A dyad of lenses for the motivational design of mhealth: Bridging the gap between health theory and app design. In 2019 IEEE International Conference on Healthcare Informatics (ICHI) (IEEE): 1-12.

[23] Asbjørnsen, R.A., Wentzel, J., Smedsrød, M.L., Hjelmeseth, J., Clark, M.M., Nes, L.S. and Van Gemert-Pijnen, J.E. (2020) Identifying persuasive design principles and behavior change techniques supporting end user values and needs in ehealth interventions for long-term weight loss maintenance: Qualitative study. Journal of medical Internet research 22(11): e22598.

[24] Alpay, L., Doms, R. and Bijwaard, H. (2019) Embedding persuasive design for self-health management systems in dutch healthcare informatics education: Application of a theory-based method. Health informatics journal 25(4): 1631-1646.

[25] Orji, R. and Moffatt, K. (2018) Persuasive technology for health and wellness: State-of-the-art and emerging trends. Health informatics journal 24(1): 66-91.

[26] Sundar, S.S., Bellur, S. and JiA, H. (2012) Motivational technologies: a theoretical framework for designing preventive health applications. In International conference on persuasive technology (Springer): 112-122.

[27] Kappen, D.L., Mirza-Babaei, P. and Nacke, L.E. (2020) Older adults' motivation for physical activity using gamified technology: An eight-week experimental study. In International Conference on Human-Computer Interaction (Springer): 292-309.

[28] Altmeyer, M., Lessel, P., Hosseini, S. and Krueger, A. (2018) Silvercycling: Evaluating persuasive strategies to promote physical activity among older adults. In Proceedings of the 2018 ACM Conference Companion Publication on Designing Interactive Systems: 45-50.

[29] Altmeyer, M., Lessel, P. and Krüger, A. (2018) Investigating gamification for seniors aged $75+$. In Proceedings of the 2018 Designing Interactive Systems Conference: 453-458.

[30] van Velsen, L., Broekhuis, M., Jansen-Kosterink, S. and op Den AKKer, H. (2019) Tailoring persuasive electronic health strategies for older adults on the basis of personal motivation: Web-based survey study. Journal of medical Internet research 21(9): e11759.

[31] Wee, S.C. and Choong, W.W. (2019) Gamification: Predicting the effectiveness of variety game design elements to intrinsically motivate users' energy conservation behaviour. Journal of environmental management 233 : 97-106.

[32] Van Houdt, L., Millecamp, M., Verbert, K. and VanDen Abeele, V. (2020) Disambiguating preferences for gamification strategies to motivate pro-environmental behaviour. In Proceedings of the Annual Symposium on Computer-Human Interaction in Play: 241-253.

[33] Hallifax, S., Lavoué, E. and Serna, A. (2020) To tailor or not to tailor gamification? an analysis of the impact of tailored game elements on learners' behaviours and motivation. In International Conference on Artificial Intelligence in Education (Springer): 216-227.

[34] Feng, W., Tu, R. and Hsieh, P. (2020) Can gamification increases consumers' engagement in fitness apps? the moderating role of commensurability of the game elements. Journal of Retailing and Consumer Services 57: 102229.

[35] Mitchell, R., Schuster, L. and Jin, H.S. (2020) Gamification and the impact of extrinsic motivation on needs satisfaction: Making work fun? Journal of Business Research 106: 323-330.

[36] Anderson, M. and Perrin, A. (2017) Tech adoption climbs among older adults. Pew research center 2017: 122.

[37] Vandendriessche, K. and De Marez, L. (2020), imec. digimeter 2019: Digitale mediatrends in vlaanderen. imec.

[38] Conci, M., Pianesi, F. and Zancanaro, M. (2010) Older Adults' Attitude Towards a Monitoring Technology. In Proceedings of the 28th Annual European Conference on Cognitive Ergonomics, ECCE '10 (New York, NY, USA: ACM): 143-146. doi:10.1145/1962300.1962328, URL http://doi .acm.org/10.1145/1962300.1962328.

[39] Davis, F.D. (1989) Perceived Usefulness, Perceived Ease of Use, and User Acceptance of Information Technology. MIS Q. 13(3): 319-340. doi:10.2307/249008.

[40] Venkatesh, V., Morris, M.G., Davis, G.B. and Davis, F.D. (2003) User Acceptance of Information Technology: Toward a Unified View. MIS Quarterly 27(3): 425478. doi:10.2307/30036540, URL http://www. jstor. org/stable/30036540.

[41] Czaja, S.J., Charness, N., Fisk, A.D., Hertzog, C., Nair, S.N., Rogers, W.A. and Sharit, J. (2006) Factors predicting the use of technology: findings from the center for research and education on aging and technology enhancement (create). Psychology and aging 21(2): 333.

[42] Young, R., Willis, E., Cameron, G. and Geana, M. (2014) "willing but unwilling": attitudinal barriers to adoption of home-based health information technology among older adults. Health informatics journal 20(2): 127-135.

[43] Mitzner, T.L., Boron, J.B., Fausset, C.B., Adams, A.E., Charness, N., Czaja, S.J., Dijkstra, K. et al. (2010) Older adults talk technology: Technology usage and attitudes. Computers in human behavior 26(6): 1710-1721.

[44] Hamari, J., Koivisto, J. and Sarsa, H. (2014) Does gamification work?-a literature review of empirical studies on gamification. In 2014 47th Hawaii international conference on system sciences (Ieee): 3025-3034.

[45] Michie, S. and Abraham, C. (2004) Interventions to change health behaviours: evidence-based or evidenceinspired? Psychology \& Health 19(1): 29-49.

[46] Michie, S., Hyder, N., Walia, A. and West, R. (2011) Development of a taxonomy of behaviour change techniques used in individual behavioural support for smoking cessation. Addictive behaviors 36(4): 315-319.

[47] Sankaran, S., Frederix, I., Haesen, M., Dendale, P., Luyten, K. and Coninx, K. (2016) A grounded approach for applying behavior change techniques in mobile cardiac tele-rehabilitation. In Proceedings of the 9th ACM International Conference on PErvasive Technologies Related to Assistive Environments: 1-8.

[48] Frederix, I., Solmi, F., Piepoli, M.F. and Dendale, P. (2017) Cardiac telerehabilitation: a novel cost-efficient care delivery strategy that can induce long-term health benefits. European journal of preventive cardiology 24(16): 
$1708-1717$

[49] Johnson, D., Deterding, S., Kuhn, K.A., Staneva, A., Stoyanov, S. and Hides, L. (2016) Gamification for health and wellbeing: A systematic review of the literature. Internet interventions 6: 89-106.

[50] Koivisto, J. and Malik, A. (2020) Gamification for older adults: A systematic literature review. The Gerontologist .

[51] Deci, E.L., Vallerand, R.J., Pelletier, L.G. and Ryan, R.M. (1991) Motivation and education: The selfdetermination perspective. Educational psychologist 26(34): 325-346.

[52] Fishbein, M. (1979) A theory of reasoned action: some applications and implications. In Nebraska Symposium on Motivation (University of Nebraska Press).

[53] Hochbaum, G., Rosenstock, I. and Kegels, S. (1952) Health belief model. United states public health service $\mathbf{1}$.

[54] Ajzen, I. (1991) The theory of planned behavior. Organizational behavior and human decision processes 50(2): 179-211.

[55] Geuens, J., Geurts, L., Swinnen, T.W., Westhovens, R. and Abeele, V.V. (2019) Mobile health features supporting self-management behavior in patients with chronic arthritis: mixed-methods approach on patient preferences. JMIR mHealth and uHealth 7(3): e12535.

[56] De Croon, R., Bezabih, A.M., Geuens, J., Wildemeersch, D., Oeyen, D., Verbert, K. and Abeele, V.V. (2019) Motivational design techniques to increase adherence to a telemonitoring therapy a study with adolescent pectus patients. In 2019 IEEE International Conference on Healthcare Informatics (ICHI) (IEEE): 1-12.

[57] Pereira, P., Duarte, E., Rebelo, F. and Noriega, P. (2014) A review of gamification for health-related contexts. In International conference of design, user experience, and usability (Springer): 742-753.

[58] Klock, A.C.T., Gasparini, I., Pimenta, M.S. and Hamari, J. (2020) Tailored gamification: A review of literature. International Journal of Human-Computer Studies : 102495.

[59] Koivisto, J. and Hamari, J. (2019) The rise of motivational information systems: A review of gamification research. International Journal of Information Management 45: 191-210.

[60] Pesare, E., Roselli, T., Corriero, N. and Rossano, V. (2016) Game-based learning and gamification to promote engagement and motivation in medical learning contexts. Smart Learning Environments 3(1): 1-21.

[61] Dugas, M., Crowley, K., Gao, G.G., Xu, T., Agarwal, R., Kruglanski, A.W. and Steinle, N. (2018) Individual differences in regulatory mode moderate the effectiveness of a pilot mhealth trial for diabetes management among older veterans. PloS one 13(3): e0192807.

[62] Ryan, R.M. and Deci, E.L. (2000) Intrinsic and Extrinsic Motivations: Classic Definitions and New Directions. Contemporary Educational Psychology 25(1): 54-67. doi:10.1006/ceps.1999.1020, URL http:// linkinghub . elsevier.com/retrieve/pii/S0361476X99910202.

[63] Ntoumanis, N., Ng, J.Y., Prestwich, A., Quested, E., Hancox, J.E., Thøgersen-Ntoumani, C., Deci, E.L. et al. (2020) A meta-analysis of self-determination theoryinformed intervention studies in the health domain: effects on motivation, health behavior, physical, and psychological health. Health Psychology Review : 1-31.

[64] Gillison, F.B., Rouse, P., Standage, M., Sebire, S.J. and Ryan, R.M. (2019) A meta-analysis of techniques to promote motivation for health behaviour change from a self-determination theory perspective. Health psychology review 13(1): 110-130.

[65] McMahon, S.K., Lewis, B., Oakes, M., Guan, W., Wyman, J.F. and Rothman, A.J. (2016) Older adults' experiences using a commercially available monitor to self-track their physical activity. JMIR mHealth and uHealth 4(2): e35.

[66] Hanson, V.L. (2009) Age and web access: the next generation. In Proceedings of the 2009 International CrossDisciplinary Conference on Web Accessibililty (W4A): 7-15.

[67] Peek, S., Luijkx, K.G., RijnaArd, M.D., Nieboer, M.E., van der Voort, C.S., Aarts, S., van Hoof, J. et al. (2016) Older adults' reasons for using technology while aging in place. Gerontology 62(2): 226-237.

[68] Czaja, S.J. and Lee, C.C. (2007) The impact of aging on access to technology. Universal Access in the Information Society 5(4): 341-349. doi:10.1007/s10209006-0060-x, URL http://1ink.springer.com/10. 1007 / s 10209-006-0060-x.

[69] Grönvall, E. and Verdezoto, N. (2013) Beyond selfmonitoring: understanding non-functional aspects of home-based healthcare technology (ACM Press): 587. doi:10.1145/2493432.2493495, URL http://dl.acm. org/citation. cfm?doid=2493432.2493495.

[70] Hauk, N., Hüffmeier, J. and Krumm, S. (2018) Ready to be a silver surfer? a meta-analysis on the relationship between chronological age and technology acceptance. Computers in Human Behavior 84: 304-319.

[71] Roque, N.A. and Воот, W.R. (2018) A new tool for assessing mobile device proficiency in older adults: the mobile device proficiency questionnaire. Journal of Applied Gerontology 37(2): 131-156.

[72] Pelletier, L.G., Tuson, K.M., Fortier, M.S., Vallerand, R.J., Briere, N.M. and Blais, M.R. (1995) Toward a new measure of intrinsic motivation, extrinsic motivation, and amotivation in sports: The sport motivation scale (sms). Journal of sport and Exercise Psychology 17(1): 3553.

[73] Kluyver, T., Ragan-Kelley, B., Pérez, F., Granger, B.E., Bussonnier, M., Frederic, J., Kelley, K. et al. (2016) Jupyter notebooks-a publishing format for reproducible computational workflows. In ELPUB: 87-90.

[74] Oliphant, T.E. (2006) A guide to NumPy, 1 (Trelgol Publishing USA).

[75] McKinney, W. et al. (2010) Data structures for statistical computing in python. In Proceedings of the 9th Python in Science Conference (Austin, TX), 445: 51-56.

[76] Hunter, J.D. (2007) Matplotlib: A 2d graphics environment. Computing in science E engineering 9(3): 90-95.

[77] Virtanen, P., Gommers, R., Oliphant, T.E., Haberland, M., Reddy, T., Cournapeau, D., Burovski, E. et al. (2020) SciPy 1.0: Fundamental Algorithms for Scientific Computing in Python. Nature Methods doi:https://doi.org/10.1038/s41592-019-0686-2.

[78] Waskom, M., Botvinnik, O., O’Kane, D., Hobson, P., Lukauskas, S., Gemperline, D.C., Augspurger, T. et al. (2017) mwaskom/seaborn: v0. 8.1 (september 2017). 
version v0.8.1 8.

[79] Triamant (2020), Triamant group, https://www. triamantgroup. com.

[80] Folstein, M.F., Folstein, S.E. and McHugh, P.R. (1975) Mini-mental state: a practical method for grading the cognitive state of patients for the clinician. Journal of psychiatric research 12(3): 189-198.

[81] Statistics, L. (2013) Spearman's rank-order correlation using spss statistics. SPSS Statistics .

[82] Vornhagen, J.B., Tyack, A. and Mekler, E.D. (2020) Statistical significance testing at chi play: Challenges and opportunities for more transparency. In Proceedings of the Annual Symposium on Computer-Human Interaction in Play: 4-18.

[83] Field, A. (2013) Discovering statistics using IBM SPSS statistics (sage), chap. Correlation, 173.

[84] Vallerand, R.J. and Ratelle, C.F. (2002) Intrinsic and extrinsic motivation: a hierarchical model. .

[85] van Roy, R., Deterding, S. and Zaman, B. (2019) Collecting pokémon or receiving rewards? how people functionalise badges in gamified online learning environments in the wild. International Journal of HumanComputer Studies 127: 62-80.

[86] Vines, J., Pritchard, G., Wright, P., Olivier, P. and Brittain, K. (2015) An Age-Old Problem: Examining the Discourses of Ageing in HCI and Strategies for Future Research. ACM Trans. Comput.-Hum. Interact. 22(1): 2:12:27. doi:10.1145/2696867, URL http://doi .acm.org/ $10.1145 / 2696867$.
[87] Bond, J., Briggs, R. and Coleman, P. (1993) The study of ageing. Ageing in society: an introduction to social gerontology: 19-52.

[88] Grönvall, E. and Kyng, M. (2013) On participatory design of home-based healthcare. Cognition, technology E work 15(4): 389-401.

[89] De Schutter, B. and Abeele, V.V. (2015) Towards a gerontoludic manifesto. Anthropology \& Aging 36(2): $112-120$.

[90] Davis, F.D. (1989) Perceived usefulness, perceived ease of use, and user acceptance of information technology. MIS quarterly: 319-340.

[91] Deci, E.L. and Ryan, R.M. (2000) The what and why of goal pursuits: Human needs and the self-determination of behavior. Psychological inquiry 11(4): 227-268.

[92] Hoque, R. and Sorwar, G. (2017) Understanding factors influencing the adoption of mhealth by the elderly: An extension of the utaut model. International journal of medical informatics 101: 75-84.

[93] HeerinK, M., Kröse, B., Evers, V. and Wielinga, B. (2010) Assessing acceptance of assistive social agent technology by older adults: the almere model. International journal of social robotics 2(4): 361-375.

[94] Petersen, F., Jacobs, M. and Pather, S. (2020) Barriers for user acceptance of mobile health applications for diabetic patients: Applying the utaut model. In Conference on e-Business, e-Services and e-Society (Springer): 61-72. 